\title{
Flaxseed Oil and Heated Flaxseed Supplements Have Different Effects on Lipid Deposition and Ileal Microbiota in Albas Cashmere Goats
}

\author{
Shulin Liu, Xue Wang, Yinhao Li, Binlin Shi, Xiaoyu Guo, Yanli Zhao and Sumei Yan *(D) \\ Inner Mongolia Key Laboratory of Animal Nutrition and Feed Science, College of Animal Science, \\ Inner Mongolia Agricultural University, Huhhot 010018, China; liushulin0723@163.com (S.L.); \\ wangxue199204@163.com (X.W.); yinhaoli2019@126.com (Y.L.); shibinlin@yeah.net (B.S.); \\ gxy_2594@163.com (X.G.); ylzhao2010@163.com (Y.Z.) \\ * Correspondence: yansmimau@163.com
}

check for updates

Citation: Liu, S.; Wang, X.; Li, Y.; Shi, B.; Guo, X.; Zhao, Y.; Yan, S. Flaxseed Oil and Heated Flaxseed Supplements Have Different Effects on Lipid Deposition and Ileal Microbiota in Albas Cashmere Goats. Animals 2021, 11, 790. https:// doi.org/10.3390/ani11030790

Academic Editors: Gabriel De La Fuente, Joaquim Balcells and Ahmad Reza Seradj

Received: 17 February 2021

Accepted: 8 March 2021

Published: 12 March 2021

Publisher's Note: MDPI stays neutral with regard to jurisdictional claims in published maps and institutional affiliations.

Copyright: (c) 2021 by the authors. Licensee MDPI, Basel, Switzerland. This article is an open access article distributed under the terms and conditions of the Creative Commons Attribution (CC BY) license (https:// creativecommons.org/licenses/by/ $4.0 /)$.
Simple Summary: With the grassland desertification intensified, pasture carrying capacity decreased, and grass seasonal changed, stall-feeding fattening has become an effective means to protect the natural environment. The stall-feeding fattening increased the cashmere goats' weight but reduced the meat quality and increased the saturated fatty acids content in muscle and fat tissue of cashmere goats. Supplementing flaxseed and flaxseed oil rich-in linolenic acid (ALA) to diet to improve meat quality is an effective nutritional regulation means. Previous research results of our team showed that compared to diet supplemented with flaxseed oil, added flaxseed increased linoleic acid biohydrogenation by reducing the Ruminobacter relative abundance and increasing the relative abundance of Prevotellaceae_UCG-001 and Fretibacterium in rumen, protected ALA away from biohydrogenation, and more n-3 polyunsaturated fatty acids entered the post-intestinal tract. Based on the previous research, this study explored whether the ALA flowing into the posterior intestine can reduce fat deposition and blood lipid by affecting intestinal microbiota. The results showed that adding flaxseed grain to diet decreased the growth performance, lipid deposition, and blood lipid content of goats by regulating the blood lipid-related enzyme activity, which positively associated with [Eubacterium]_coprostanoligenes_group, but negatively associated with unclassified_f_Peptostreptococcaceae, Intestinibacter, and Ruminococcus_2.

Abstract: The present study investigated the effect of flaxseed grain or flaxseed oil on ileal microbiota and lipid deposition of cashmere goats. Sixty kid goats (average body weight $18.6 \pm 0.1 \mathrm{~kg}$ ) were allocated to three treatments, fed for 90 days, with control treatment: basal diet (CON, total-mixed ration), experimental treatment: basal diet with added flaxseed oil (LNO), experimental treatment: basal diet with added heated flaxseed grain (HLS). The final body weight, body weight gain, the weight of kidney fat, omental fat, tail fat, and fat tissue, the activity of fatty acid synthetase, acetyl-coa carboxylase, and malic dehydrogenase, and the relative abundance (RA) of unclassified_f_Peptostreptococcaceae and Intestinibacter were remarkably higher in the LNO treatment than in the HLS treatment, but the [Eubacterium]_coprostanoligenes_group RA showed the opposite result. The content of triglyceride, cholesterol, and low-density lipoprotein cholesterol were significantly higher in the CON and LNO treatments than in the HLS treatment, while the hormone-sensitive lipase activity and the non-esterified fatty acid content showed the opposite result. In conclusion, the flaxseed grain is more efficient than flaxseed oil in ameliorating the blood lipid profiles and it is a potential product for decreasing the lipid deposition of cashmere goats.

Keywords: flaxseed; flaxseed oil; lipid deposition; ileal microbiota; cashmere goats 


\section{Introduction}

Albas white cashmere goat is a world famous local breed producing cashmere and meat, coming from the plateau region of Ordos, Inner Mongolian, China. In recent years, due to the limitation of natural grassland resources, degeneration of the grassland, and the increase of mutton market demand, the fattening pattern has changed from traditional pasture fattening to feedlot fattening, which can alleviate the pressure of grassland and increase the economic benefits. However, changes in fattening pattern mean the alteration of diet nutritional level, which can cause metabolic changes in livestock. For lambs fed an energy-restricted feeding sequence program to mimic the seasonal changes of the natural grasslands, the results indicated that sequentially restricting metabolizable energy intake resulted in a reduction of body weight, serum glucose (GLU) and triglyceride (TG) concentration [1]. Feeding high-energy diets increased serum GLU and cholesterol (CHO) content in ewes [2]. Chen et al. reported that the diet with low ratio of forage to concentrate $(\mathrm{F}: \mathrm{C}=50: 50)$ had a higher concentration of serum high-density lipoprotein cholesterol $(\mathrm{HDL}-\mathrm{C})$ in Yak than the diet with high-forage $(\mathrm{F}: \mathrm{C}=70: 30, \mathrm{~F}: \mathrm{C}=60: 40)$ groups [3]. Previous research reported an increase of plasma total lipids, $\mathrm{CHO}$, TG, phospholipids, and nonesterified fatty acid (NEFA) in ruminant, which lead to lipid infiltration of the liver, and this favors the appearance of ketoacidosis, to the detriment of the health and reproductive performance of the animal [4]. Therefore, the increasing studies ameliorating the lipid metabolism of ruminants in stall fattening are very necessary. Manipulating the dietary fat might be a feasible approach to regulate blood lipid metabolism, however, very little information on ruminants is available. Flaxseed contains $32 \%$ to $45 \%$ of its mass as oil, of which $51 \%$ to $55 \%$ is a-linolenic acid (ALA) and $15 \%$ to $18 \%$ is linoleic acid, and it includes the flax lignan complex [5]. The main components of flaxseed oil are saturated fatty acid (SFA, 9\%), monounsaturated fatty acid (18\%), and ALA (57\%) [6]. ALA is the most important fatty acid in flaxseed oil and flaxseed, which are the most important functional phytochemicals in flaxseeds for human health [7], and it is the precursor to the synthesis of eicosapentaenoic acid (EPA) and docosahexaenoic acid (DHA). The research observed that the addition of flaxseed could reduce the serum $\mathrm{CHO}$ concentration of cows [8], and another study reported that dietary calcium ALA could significantly reduce serum $\mathrm{CHO}, \mathrm{TG}$, and low-density lipoprotein cholesterol (LDL-C) levels in high-fat-fed mice [9]. Our previous study showed that flaxseed oil and flaxseed grain supplemented in diet showed different effects on increasing the concentration of ALA, EPA, DHA, and n-3 polyunsaturated fatty acids (n-3PUFA) in plasma and tissues in Albas cashmere goats, and flaxseed grain was more efficient [10]. n-3 PUFAs reduced plasma TG by approximately $20-30 \%$ and decreased the substrate of oxidative LDL-C and remnant CHO taken up by macrophages $[11,12]$. These researches hinted that flaxseed and flaxseed oil rich in n-3 PUFA may regulate the blood lipid profiles and lipid deposition, and they probably have different influences, but limited data are available, and the mechanism is also unclear.

Gut microbiota may be involved in the regulation of serum lipid levels and lipid accumulation, because it plays important roles in host metabolism [13]. Wen et al. reported that the genus Methanobrevibacter and the species Mucispirillum schaedleri were strongly associated with fat deposition in gut of chickens [14]. The bacteria in cecum of pigs positively associating with LDL-C/HDL-C in serum belongs to Proteobacteria, which is associated with inflammation [15]. An increase of serum LDL-C, very LDL-C and lipids concentration by dietary butyrate glycerides in broilers, not only significantly increased the Bifdobacterium abundance but also boosted the species diversity, and the results suggested the potential contribution of intestinal bacteria to lipid metabolism/energy homeostasis in broilers [16]. The previous research results of our team showed that compared to diet supplemented with linseed oil, added flaxseed increased linoleic acid biohydrogenation by reducing the relative abundance of Ruminobacter and increasing the relative abundance of Prevotellaceae_UCG-001 and Fretibacterium in rumen, protected ALA away from biohydrogenation, and lead to more n-3 PUFAs entering the post-intestinal tract [17]. The previous studies have shown that except for the rumen and large intestine, the ileum also serves 
as an indispensable fermentation site in goats $[18,19]$. Yan et al. reported that there is a larger number of cellulolytic bacteria in sheep ileum, particularly Clostridium cluster IV [20]. Therefore, we hypothesized that ALA-rich flaxseed oil and flaxseed grain supplements have different effects in ameliorating blood lipid profiles and lipid deposition in Albas cashmere goats, and the mechanism is probably involved in altering ileal microbial composition. The current study aimed to test whether supplementing flaxseed oil and flaxseed grain in diet has different regulation on lipid deposition and ileal microbiota community in Albas cashmere goats, and to explain the possible mechanism of flaxseed oil and flaxseed in ameliorating lipid deposition.

\section{Materials and Methods}

The experiment was conducted in the experimental farm of Inner Mongolia Agricultural University (Hohhot, China). All animal procedures were performed under the national standard Guidelines for Ethical Review of Animal Welfare (GB/T 35892-2018).

\subsection{Experimental Design, Diet, and Feeding Management}

A single-factor completely randomized design was used. Sixty 4-month-old castrated Albas cashmere male kid goats were selected from a farm, at Etuoke Town, Inner Mongolia, with an initial live weight of $18.6 \pm 0.1 \mathrm{~kg}$, and were randomly assigned to three treatments, with each treatment comprising 4 units of 5 goats. The control group (CON) was fed the basal diet with no supplementation. The experimental group was fed the flaxseed oil-supplemented diets (LNO) prepared by manually blending the oil thoroughly into the ground concentrate to ensure homogenous distribution of the oil in the ration. Another experimental group was fed the basal diet supplemented with heated flaxseed grain (HLS, the flaxseed contains about $36 \%$ oil and it was stir roasted at $120{ }^{\circ} \mathrm{C}$ for $10 \mathrm{~min}$ ), which provided the same content of flaxseed oil as the LNO group. The nutrition levels of the diet could meet the needs of growing cashmere kids, according to the feeding standard of meat-producing sheep and goats (NY/T816, 2004 [21]; Table 1). The trial consisted of a 14-day adaptation period and a 90-day treatment period, including early (1 to 30 days), medium (31 to 60 days), and late (61 to 90 days) fattening stages. The diet was offered to goats twice daily at 08:30 am and $16: 30 \mathrm{pm}$ as total mixed ration (concentrate to forage ratio of 50:50) and the goats were given free access to drinking water. To estimate feed intake for five goats in each pen, refusals were collected and weighed $30 \mathrm{~min}$ before each feeding, at 08:00 am daily. All goats were weighed (before feeding in the morning) on day 0 (initial body weight, IBW) and days 90 (final body weight, FBW) of the measurement periods to determine changes in body weight (total body weight gain, BWG).

\subsection{Sample Collection}

At the end of the experiment, 2 goats from each experimental unit ( 8 goats per treatment) were randomly selected for slaughtering by exsanguination. Before slaughter, the goats were prevented from consuming feed for $24 \mathrm{~h}$ and from drinking for $2 \mathrm{~h}$. Jugular blood $(20 \mathrm{~mL})$ was sampled into Vacutainer tubes after the goats were prevented from consuming feed for $12 \mathrm{~h}$. Blood was centrifuged at $3000 \times g$ for 15 min and serum was harvested, and at last stored at $-20{ }^{\circ} \mathrm{C}$ for lipid profiles and enzymatic activity analysis. Immediately after death, the ileal digesta were collected, flash-frozen by liquid nitrogen, and stored at $-80^{\circ} \mathrm{C}$ for microbial diversity analysis. 
Table 1. The composition and nutrient levels of CON, LNO, and HLS group (dry-matter basis, DM basis).

\begin{tabular}{|c|c|c|c|c|c|c|c|c|c|}
\hline \multirow{2}{*}{ Ingredients } & \multicolumn{3}{|c|}{1 to 30 Days } & \multicolumn{3}{|c|}{31 to 60 Days } & \multicolumn{3}{|c|}{61 to 90 Days } \\
\hline & $\mathrm{CON}$ & LNO & HSL & $\mathrm{CON}$ & LNO & HSL & $\mathrm{CON}$ & LNO & HSL \\
\hline Alfalfa & 25.00 & 25.00 & 25.00 & 15.00 & 15.00 & 15.00 & 12.50 & 12.50 & 12.50 \\
\hline Corn stalk & 5.00 & 5.00 & 5.00 & 20.00 & 20.00 & 20.00 & 25.00 & 25.00 & 25.00 \\
\hline Oat & 20.00 & 20.00 & 20.00 & 15.00 & 15.00 & 15.00 & 12.50 & 12.50 & 12.50 \\
\hline Corn & 28.41 & 23.37 & 23.17 & 30.80 & 30.40 & 29.90 & 31.30 & 29.90 & 29.40 \\
\hline Soybean meal $46 \%$ & 11.70 & 10.50 & 11.50 & 9.50 & 11.40 & 11.90 & 8.00 & 10.40 & 10.90 \\
\hline $\begin{array}{l}\text { Distillers dried grains with solubles, } \\
\text { DDGS }\end{array}$ & 3.00 & 7.24 & 7.74 & 4.00 & 0.50 & 0.50 & 4.00 & 0.50 & 0.50 \\
\hline Flaxseed meal & 4.80 & 4.80 & 0.00 & 3.50 & 3.50 & 0.00 & 4.50 & 4.50 & 0.00 \\
\hline Flaxseed & 0.00 & 0.00 & 5.50 & 0.00 & 0.00 & 5.50 & 0.00 & 0.00 & 7.00 \\
\hline Flaxseed oil & 0.00 & 2.00 & 0.00 & 0.00 & 2.00 & 0.00 & 0.00 & 2.50 & 0.00 \\
\hline Premix ${ }^{(1)}$ & 0.50 & 0.50 & 0.50 & 0.50 & 0.50 & 0.50 & 0.50 & 0.50 & 0.50 \\
\hline Limestone & 0.2 & 0.2 & 0.2 & 0.2 & 0.2 & 0.2 & 0.2 & 0.2 & 0.2 \\
\hline $\mathrm{CaHPO}_{4}$ & 0.2 & 0.2 & 0.2 & 0.2 & 0.2 & 0.2 & 0.2 & 0.2 & 0.2 \\
\hline $\mathrm{NaCl}$ & 0.54 & 0.54 & 0.54 & 0.50 & 0.50 & 0.50 & 0.50 & 0.50 & 0.50 \\
\hline $\mathrm{NaHCO}_{3}$ & 0.35 & 0.35 & 0.35 & 0.80 & 0.80 & 0.80 & 0.80 & 0.80 & 0.80 \\
\hline $\mathrm{MgO}$ & 0.30 & 0.30 & 0.30 & 0.00 & 0.00 & 0.00 & 0.00 & 0.00 & 0.00 \\
\hline Total & 100.00 & 100.00 & 100.00 & 100.00 & 100.00 & 100.00 & 100.00 & 100.00 & 100.00 \\
\hline \multicolumn{10}{|l|}{ Nutrient levels } \\
\hline Digestible energy, DE MJ/Kg DM ${ }^{(2)}$ & 12.83 & 13.09 & 13.06 & 12.87 & 13.00 & 12.96 & 12.74 & 13.09 & 13.05 \\
\hline Dry Matter, DM/\% & 88.02 & 88.36 & 88.24 & 89.14 & 89.36 & 89.32 & 87.09 & 87.02 & 87.03 \\
\hline Crude protein, CP g/kg DM & 188.73 & 188.13 & 188.20 & 162.84 & 158.71 & 159.69 & 153.52 & 151.34 & 151.85 \\
\hline Ether extract, EE g/kg DM & 29.12 & 53.97 & 53.97 & 28.99 & 45.84 & 46.14 & 26.85 & 48.99 & 49.92 \\
\hline $\begin{array}{l}\text { Neutral Detergent Fiber, NDF g/kg } \\
\text { DM }\end{array}$ & 425.31 & 431.18 & 441.6 & 448.6 & 427.41 & 439.12 & 457.42 & 436.06 & 450.68 \\
\hline Acid Detergent Fiber, ADF g/kg DM & 232.2 & 237.71 & 243.3 & 242.59 & 235.23 & 248.4 & 247.69 & 240.32 & 256.96 \\
\hline Calcium, Ca g/kg DM & 11.25 & 11.11 & 11.00 & 10.48 & 10.89 & 10.78 & 10.26 & 10.67 & 10.56 \\
\hline Phosphorus, $\mathrm{P}$ g/kg DM & 4.65 & 4.67 & 4.78 & 4.50 & 4.44 & 4.56 & 4.31 & 4.22 & 4.33 \\
\hline
\end{tabular}

(1) Per kilogram of premix provided the following: iron (Fe) $4 \mathrm{~g}$, copper $(\mathrm{Cu}) 0.8 \mathrm{~g}$, zinc ( $\mathrm{Zn}) 5 \mathrm{~g}$, manganese (Mn) $3 \mathrm{~g}$, iodine (I) $30 \mathrm{mg}$, selenium (Se) $30 \mathrm{mg}$, cobalt (Co) $25 \mathrm{mg}$, vitamin (VA) 600,000 IU (International Unit), vitamin D (VD3) 250,000 IU, vitamin E (VE) 1250 IU, vitamin K (VK3) $180 \mathrm{mg}$, vitamin B1 (VB1) $35 \mathrm{mg}$, vitamin B2 (VB2) $850 \mathrm{mg}$, vitamin B6 (VB6) 90 mg, nicotinic acid $2200 \mathrm{mg}$, D-pantothenic acid $1700 \mathrm{mg}$, vitamin B12 (VB12) $3 \mathrm{mg}$, biotin $14 \mathrm{mg}$, folic acid $150 \mathrm{mg}$. (2) Digestible energy was calculated based on the ingredients of the diet and their digestible energy content, not based on the actual dry matter intake. CON: basal diet; LNO: basal diet added with flaxseed oil; HLS: basal diet added with heated flaxseed grain.

\subsection{Chemical Analysis}

The concentrations of TG, CHO, LDL-C, and HDL-C in serum were analyzed in an automatic biochemical analyzer (L-8900) using commercially available kits (Lepu Diagnostics Co., Ltd., Beijing, China). The concentrations of NEFA, GLU, and $\beta$-hydroxybutyric acid (BHBA) in serum were analyzed through commercially available kits (Nanjing Jiancheng Bioengineering Institute, Nanjing, Jiangsu, China). The quantity of acetyl-coa carboxylase (ACC, CK-E75273), fatty acid synthetase (FAS, CK-E75339), malic dehydrogenase (MDH, CK-E75029), lipoprotein lipase (LPL, CK-E75274), hormone-sensitive lipase (HSL, CKE75402), and lipase (LPS, CK-E75263) were measured by enzyme-linked immunosorbent assay (ELISA) kits (QUANZHOU RUIXIN BIOTECHNOLOGY CO., LTD., Quanzhou, Fujian, China), and the experiments were performed strictly according to the manufacturer's instructions. Meanwhile, the standard curves of enzymes were established. Briefly, $10 \mu \mathrm{L}$ serum sample and $40 \mu \mathrm{L}$ sample diluent were added to the coated plate, and $100 \mu \mathrm{L}$ diluted enzyme-labeled antibody was added to the plate, incubated at $37^{\circ} \mathrm{C}$ for $1 \mathrm{~h}$, then washed five times with phosphate-buffered saline (PBS) (let stand for $1 \mathrm{~min}$ ). $100 \mu \mathrm{L}$ substrate Tetramethylbenzidine (TMB) was added and avoided light incubation at $37^{\circ} \mathrm{C}$ for $15 \mathrm{~min}$, the reaction was terminated with $50 \mu \mathrm{L} 2 \mathrm{M} \mathrm{H}_{2} \mathrm{SO}_{4}$, and the optical density (OD) was measured at $450 \mathrm{~nm}$.

\section{4. $16 S$ rRNA Gene Sequencing and Operational Taxonomic Units (OTUs) Picking}

\subsubsection{DNA Extraction and Checking}

Five ileal digesta samples from each treatment group were selected to extract the microbial DNA using the E.Z.N.A. ${ }^{\circledR}$ soil DNA Kit (Omega Bio-tek, Norcross, GA, USA) according to the instruction manual. The final DNA concentration and OD (Optical 
Density) 260/280 values were determined by NanoDrop 2000 UV-vis (ultraviolet-visible) spectrophotometer (Thermo Scientific, Wilmington, NC, USA), and DNA quality was checked through $1 \%$ agarose gel electrophoresis.

\subsubsection{PCR (Polymerase Chain Reaction) Amplification and Checking}

The amplified region is V3-V4 hypervariable regions of the bacteria 16S rRNA gene. The amplified primers are 338F (5'-ACCHOCTACGGGAGGCAGCAG-3') and 806R $\left(5^{\prime}-\right.$ GGACTACHVGGGTWCHOTAAT-3'), and are universal primers. The procedure of PCR reactions was as follows: 3 min of denaturation at $95^{\circ} \mathrm{C}, 27$ cycles of $30 \mathrm{~s}$ at $95{ }^{\circ} \mathrm{C}, 30 \mathrm{~s}$ for annealing at $55^{\circ} \mathrm{C}$, and $45 \mathrm{~s}$ for elongation at $72{ }^{\circ} \mathrm{C}$, and a final extension at $72{ }^{\circ} \mathrm{C}$ for $10 \mathrm{~min}$. The mixed volume of PCR reactions was $20 \mu \mathrm{L}: 4 \mu \mathrm{L}$ of $5 \times$ FastPfu Buffer, $2 \mu \mathrm{L}$ of $2.5 \mathrm{mM}$ dNTPs (Deoxynucleotide Triphosphates), $0.8 \mu \mathrm{L}$ of each primer $(5 \mu \mathrm{M}), 0.4 \mu \mathrm{L}$ of FastPfu Polymerase, and $10 \mathrm{ng}$ of template DNA. The PCR products were extracted from a $2 \%$ agarose gel and further purified using the AxyPrep DNA Gel Extraction Kit (Axygen Biosciences, Union City, CA, USA) and quantified using QuantiFluor ${ }^{\mathrm{TM}}$-ST (Promega, Madison, WI, USA) according to the instruction manual.

\subsubsection{Illumina MiSeq Sequencing}

Purified amplicons were pooled on an Illumina MiSeq PE300 instrument (Illumina, San Diego, CA, USA) which were equimolar and paired-end sequenced $(2 \times 300)$ according to the standard protocols by Majorbio Bio-Pharm Technology Co. Ltd. (Shanghai, China).

\subsubsection{Bioinformatics}

Raw data was filtered and analyzed using QIIME (Quantitative Insights into Microbial Ecology, version 1.9.1) software, quality-filtered by Trimmomatic and merged by FLASH (Fast Length Adjustment of Short Reads). Low-quality reads were removed with the following criteria: (i) The reads were truncated at any site receiving an average quality score $<20$ over a 50 bp sliding window, (ii) primers' matching allowed 2-nucleotide mismatching, and reads containing ambiguous bases were removed, and (iii) sequences with an overlap longer than $10 \mathrm{bp}$ were merged according to their overlap sequence. The assembled sequences were assigned to operational taxonomic units (OTUs) at $97 \%$ similarity cutoff using UPARSE (Highly Accurate OTU Sequences from Microbial Amplicon Reads, version 7.1, http:/ / drive5.com/uparse/, 30 September 2013) and chimeric sequences were identified and removed using UCHIME (Chimera Prediction for Amplicon Sequencing). OTUs were used for $\alpha$-diversity (Coverage, Sobs, ACE, Chao, Shannon and Simpson) analysis. OTUs were taxonomically analyzed by the Ribosomal Database Project (RDP) Classifier algorithm (http://rdp.cme.msu.edu/, 30 September 2016). The rarefaction curves' analysis with Mothur v.1.21.1 was performed to reflect the sequence depth. Principal coordinate analysis (PCoA) was performed using the weighted Unifrac distance with R Language.

\subsection{Statistical Analysis}

The data of growth performance, organ weight, blood parameters, and enzymatic activity were analyzed in a completely randomized design using the Proc Mixed procedure of SAS (SAS Inst. Inc., Cary, NC, USA). The model was $Y_{i j}=\mu+T_{i}+P_{j}+T_{i} \times P_{j}+\varepsilon_{i j}$, where $Y_{i j}$ was the dependent, continuous variable, $\mu$ was the overall mean, $T_{i}$ was the fixed effect of diet treatment ( $i=$ basal diet, flaxseed oil, or flaxseed grain), $P_{j}$ was the random effect of pen $(\mathrm{j}=1,2,3$, and 4$), \mathrm{Ti} \times \mathrm{Pj}$ was the fixed effect of the interaction between diet and pen, and $\varepsilon_{\mathrm{ij}}$ was the residual error. The mixed model included fixed effects of diet and random effects of pen. Pen was considered the experimental unit and the repeated measurement. The model used to analyze body weight gain considers 4 replicates (number of pens), each with 5 observations (number of goats): organ weight, blood parameters, and enzymatic activity consider 4 replicates (number of pens), each with 2 observations (number of goats), for each treatment. Specifically, the model used to study feed intake considers 4 replicates (number of pens), each with 1 observation. The results are presented 
as the mean values and standard error of the mean (SEM). Data means significance was declared at $p \leq 0.05$ and tendencies were considered at $0.05<p \leq 0.10$.

For evaluation of bacterial diversity indexes, the bacteria community structure at phylum and genus level, a one-way analysis of variance (ANOVA) and Duncan's multiple range tests were carried out in SAS (SAS Inst. Inc., Cary, NC, USA). The results are presented as the mean values and SEM. Spearman correlation was used to correlate the growth performance, lipid deposition, blood lipid profiles, and blood lipid-related enzyme activity with the top 20 most relatively abundant bacterial genera through $\mathrm{R}$ Language (pheatmap package). Correlations with $p \leq 0.05$ for the linear model were considered as significant.

\section{Results}

\subsection{Growth Performance and Lipid Deposits}

As indicated in Tables 2 and 3, compared with the CON and HLS groups, the FBW, BWG, fat tissue weight, omental fat weight, and the percentage of fat tissue and omental fat to live body weight were significantly increased in the LNO group $(p<0.05)$, but the HLS group did not differ from the CON group. Compared with the HLS group, the weight of kidney fat and tail fat were remarkably increased in the LNO group $(p=0.041, p=0.037)$, but the CON group did not differ from either LNO or HLS groups.

Table 2. The effect of dietary flaxseed oil or flaxseed supplementation on the growth performance in Albas cashmere goats.

\begin{tabular}{cccccc}
\hline Items & CON & LNO & HLS & SEM & $p$-Value \\
\hline $\begin{array}{c}\text { Feed Intake } \\
\text { (kg/day/per) }\end{array}$ & 0.72 & 0.79 & 0.71 & 0.041 & 0.379 \\
$\begin{array}{c}\text { Initial Body } \\
\text { Weight/kg }\end{array}$ & 18.65 & 18.54 & 18.51 & 0.245 & 0.915 \\
$\begin{array}{c}\text { Final Body Weight/kg } \\
\text { Total Body Weight }\end{array}$ & $26.74^{\mathrm{B}}$ & $28.14^{\mathrm{A}}$ & $26.51^{\mathrm{B}}$ & 0.370 & 0.006 \\
$\quad 8.03^{\mathrm{B}}$ & $9.80^{\mathrm{A}}$ & $7.95^{\mathrm{B}}$ & 0.382 & 0.0001 \\
\hline
\end{tabular}

A, B Means within the same row not followed by the same letters are significantly different at $p \leq 0.05$, whereas the differences were considered to be a statistical trend when $0.05<p \leq 0.10$. CON: basal diet; LNO: basal diet added with flaxseed oil; HLS: basal diet added with heated flaxseed grain. SEM: standard error of the mean.

Table 3. The effect of dietary flaxseed oil or flaxseed supplementation on the lipid deposits in Albas cashmere goats.

\begin{tabular}{|c|c|c|c|c|c|}
\hline Items & $\mathrm{CON}$ & LNO & HLS & SEM & $p$-Value \\
\hline \multicolumn{6}{|c|}{ Fat Tissue Weight/g } \\
\hline Kidney Fat & $129.93 \mathrm{AB}$ & $153.91^{\mathrm{A}}$ & $120.63^{\mathrm{B}}$ & 8.352 & 0.041 \\
\hline Omental Fat & $729.31^{\text {B }}$ & $1053.55^{\mathrm{A}}$ & $696.62^{B}$ & 12.006 & $<0.0001$ \\
\hline Mesenteric Fat & 487.49 & 547.97 & 417.84 & 50.527 & 0.231 \\
\hline Tail Fat & $12.39 \mathrm{AB}$ & $14.70^{\mathrm{A}}$ & $11.16^{\mathrm{B}}$ & 0.853 & 0.037 \\
\hline Fat Tissue & $1473.59^{\mathrm{B}}$ & $1843.90^{\mathrm{A}}$ & $1249.60^{\mathrm{B}}$ & 107.680 & 0.007 \\
\hline \multicolumn{6}{|c|}{ Percentage of Live Body Weight/\% } \\
\hline Kidney Fat & 0.50 & 0.54 & 0.47 & 0.030 & 0.294 \\
\hline Omental Fat & $2.77^{\mathrm{B}}$ & $4.10^{\mathrm{A}}$ & $2.83^{\mathrm{B}}$ & 0.096 & $<0.0001$ \\
\hline Mesenteric Fat & 1.88 & 1.94 & 1.79 & 0.153 & 0.797 \\
\hline Tail Fat & 0.05 & 0.05 & 0.04 & 0.004 & 0.771 \\
\hline Fat Tissue & $5.19^{\mathrm{B}}$ & $6.45^{\mathrm{A}}$ & $5.07^{\mathrm{B}}$ & 0.151 & $<0.0001$ \\
\hline
\end{tabular}

$\overline{\mathrm{A}, \mathrm{B}}$ Means within the same row not followed by the same letters are significantly different at $p \leq 0.05$, whereas the differences were considered to be a statistical trend when $0.05<p \leq 0.10$. CON: basal diet; LNO: basal diet added with flaxseed oil; HLS: basal diet added with heated flaxseed grain. SEM: standard error of the mean.

\subsection{Blood Lipid Profiles}

As shown in Table 4, compared with the HLS group, the contents of TG, CHO, and LDL-C were significantly increased in the CON and LNO groups $(p=0.001, p=0.001$, 
$p=0.001)$, the NEFA content showed the opposite result $(p=0.003)$, and the LNO group did not differ from the CON group. Compared with the CON and HLS treatments, the BHBA content significantly decreased in the LNO treatment $(p=0.002)$, and there was no difference between the CON and HLS treatments. The HDL-C content tended to be remarkably higher in the LNO and HLS groups than the CON group $(p=0.062)$, but the HLS group did not differ from the LNO group. The GLU content tended to be remarkably higher in the LNO treatment $(p=0.062)$ than the CON and HLS treatments, but the HLS treatment did not differ from the $\mathrm{CON}$ treatment.

Table 4. The effect of dietary flaxseed oil or flaxseed supplementation on the blood lipid profiles in Albas cashmere goats.

\begin{tabular}{cccccc}
\hline Items & CON & LNO & HLS & SEM & $p$-Value \\
\hline TG (mmol/L) & $0.63^{\mathrm{A}}$ & $0.64^{\mathrm{A}}$ & $0.48^{\mathrm{B}}$ & 0.036 & 0.001 \\
CHO (mmol/L) & $1.87^{\mathrm{A}}$ & $2.11^{\mathrm{A}}$ & $1.57^{\mathrm{B}}$ & 0.100 & 0.001 \\
LDL-C (mmol/L) & $0.54^{\mathrm{A}}$ & $0.57^{\mathrm{A}}$ & $0.40^{\mathrm{B}}$ & 0.026 & 0.001 \\
HDL-C (mmol/L) & $0.82^{\mathrm{m}}$ & $0.86^{\mathrm{m}}$ & 0.87 & 0.015 & 0.062 \\
GLU (mmol/L) & $3.64^{\mathrm{B}}$ & $3.88^{\mathrm{B}}$ & 3.72 & 0.093 & 0.062 \\
NEFA (nmol/L) & $0.23^{\mathrm{B}}$ & $0.16^{\mathrm{B}}$ & $0.36^{\mathrm{A}}$ & 0.035 & 0.003 \\
BHBA (mmol/L) & $0.20^{\mathrm{A}}$ & $0.14^{\mathrm{B}}$ & $0.23^{\mathrm{A}}$ & 0.013 & 0.002 \\
\hline
\end{tabular}

A, B Means within the same row not followed by the same letters are significantly different at $p \leq 0.05$, whereas the differences were considered to be a statistical trend when $0.05<p \leq 0.10$. CON: basal diet; LNO: basal diet added with flaxseed oil; HLS: basal diet added with heated flaxseed grain. SEM: standard error of the mean. TG: triglyceride; CHO: cholesterol; LDL-C: low-density lipoprotein cholesterol; HDL-C: high-density lipoprotein cholesterol; GLU: glucose; NEFA: non-esterified fatty acid; BHBA: $\beta$-hydroxybutyric acid.

\subsection{The Quantity of Enzymes Related to Blood Lipid Metabolism}

As indicated in Table 5, compared with the CON and HLS treatments, the ACC and MDH quantity remarkably increased in the LNO treatment $(p=0.015, p=0.010)$, but there was no difference between the CON and HLS treatments. Compared with the CON and LNO treatments, the HSL quantity significantly increased in the HLS treatment $(p=0.002)$, but there was no difference between the CON and LNO treatments. The FAS quantity was significantly higher in the LNO treatment than the HLS treatment $(p=0.016)$, but the CON treatment did not differ from either LNO or HLS treatments.

Table 5. The effect of dietary flaxseed oil or flaxseed supplementation on the enzymes related to lipid metabolism in blood of Albas cashmere goats.

\begin{tabular}{cccccc}
\hline Items & CON & LNO & HLS & SEM & $p$-Value \\
\hline FAS $(\mathrm{ng} / \mathrm{mL})$ & $26.07^{\mathrm{AB}}$ & $31.07^{\mathrm{A}}$ & $22.57^{\mathrm{B}}$ & 1.748 & 0.016 \\
ACC $(\mathrm{ng} / \mathrm{mL})$ & $82.26^{\mathrm{B}}$ & $100.38^{\mathrm{A}}$ & $81.15^{\mathrm{B}}$ & 4.365 & 0.015 \\
MDH $(\mathrm{ng} / \mathrm{mL})$ & $18.24^{\mathrm{B}}$ & $19.24^{\mathrm{A}}$ & $17.58^{\mathrm{B}}$ & 0.470 & 0.010 \\
LPL $(\mathrm{ng} / \mathrm{mL})$ & 340.24 & $334.40^{\mathrm{B}}$ & 364.28 & 12.551 & 0.134 \\
HSL $(\mathrm{ng} / \mathrm{mL})$ & $7.21^{\mathrm{B}}$ & $7.34^{\mathrm{B}}$ & $9.55^{\mathrm{A}}$ & 0.393 & 0.002 \\
LPS $(\mathrm{ng} / \mathrm{mL})$ & $9.80^{\mathrm{A}}$ & 10.00 & 8.87 & 0.424 & 0.176 \\
\hline
\end{tabular}

$\overline{\mathrm{A}, \mathrm{B}}$ Means within the same row not followed by the same letters are significantly different at $p \leq 0.05$, whereas the differences were considered to be a statistical trend when $0.05<p \leq 0.10$. CON: basal diet; LNO: basal diet added with flaxseed oil; HLS: basal diet added with heated flaxseed grain. SEM: standard error of the mean. FAS: fatty acid synthetase; ACC: acetyl-coa carboxylase; MDH: malic dehydrogenase; LPL: lipoprotein lipase; HSL: hormone-sensitive lipase; LPS: lipase.

\subsection{Microbial Diversity of Ileum Digesta \\ 3.4.1. Sampling Depth}

As shown in Table 6, after optimizing the original data, 271,857, 281,019, and 253,906 high-quality valid sequences were obtained in the CON, LNO, and HLS groups, respectively. On the basis of $97 \%$ species similarity, 563, 524, and 594 OTUs were separately obtained from samples in the CON, LNO, and HLS groups. Nearly 806,782 sequences were generated for ileum digesta bacteria, with an average of 54,371,56,204, and 50,781 
sequences for each sample in the CON, LNO, and HLS groups, respectively. Both the rarefaction curves (Figure 1) and the high coverage value (from 0.9985 to 0.9987 , Table 4) showed that the sampling depth is enough to estimate bacterial diversity.

Table 6. Sequence data of bacteria in ileum digesta.

\begin{tabular}{ccccc}
\hline Group & $\begin{array}{c}\text { Optimized } \\
\text { Sequences }\end{array}$ & OTUs & $\begin{array}{c}\text { Average Optimized } \\
\text { Sequences of Sample }\end{array}$ & $\begin{array}{c}\text { Average Length of } \\
\text { Optimized Sequence }\end{array}$ \\
\hline CON & 271,857 & 563 & 54,371 & 429 \\
LNO & 281,019 & 524 & 56,204 & 431 \\
HLS & 253,906 & 594 & 50,781 & 433 \\
\hline
\end{tabular}

CON: basal diet; LNO: basal diet added with flaxseed oil; HLS: basal diet added with heated flaxseed grain. OTUs: operational taxonomic units.

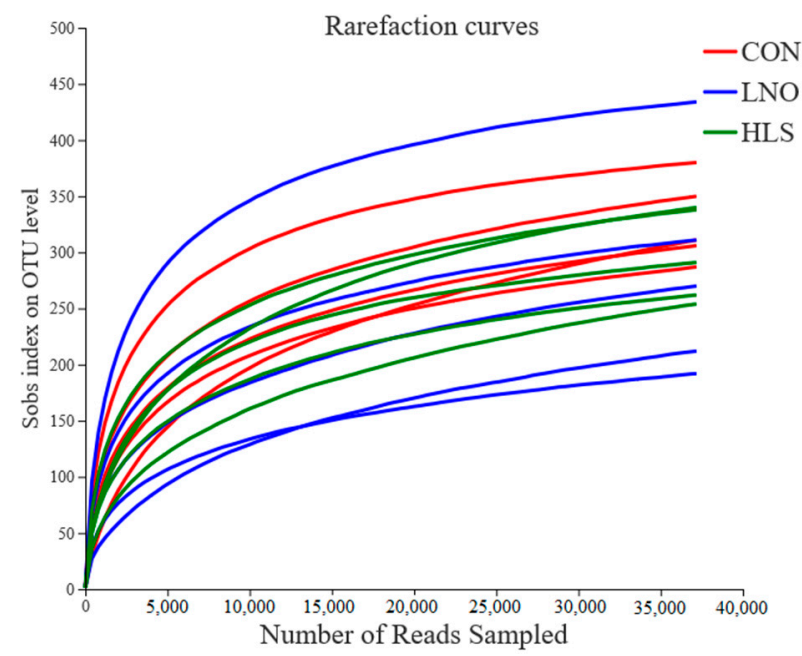

Figure 1. The OTU rarefaction curves of the ileum digesta bacterial communities. Curves were drawn using the least sequenced sample as the upper limit for the rarefactions. Each color represents one treatment: The red curves represent kids fed the basal diet $(\mathrm{CON})$, the blue curves represent kids fed the basal diet supplemented with flaxseed oil (LNO), and the green curves represent kids fed the basal diet supplemented with heated flaxseed grain (HLS).

\subsubsection{Ileum Microbiota $\alpha$ - and $\beta$-Diversity}

As indicated in Table 7, compared with the LNO group, the Sobs (the number of OTUs), ACE (the ACE estimator) and Chao (the Chao estimator) index significantly increased in CON and HLS groups $(p=0.038, p=0.001, p=0.019)$, but there was no significant difference between CON and HLS groups. The principal coordinate analysis (PCoA) plots (Figure 2) demonstrate dissimilarities between the CON group, the LNO group, and the HLS group.

Table 7. The $\alpha$-diversity indexes of bacteria in ileum digesta.

\begin{tabular}{cccccc}
\hline Index & CON & LNO & HLS & SEM & $p$-Value \\
\hline Coverage & $0.9985^{\mathrm{A}}$ & $0.9987^{\mathrm{B}}$ & $0.9985^{\mathrm{A}}$ & 0.0002 & 0.722 \\
Sobs & $325.25^{\mathrm{A}}$ & $253.00^{\mathrm{B}}$ & $354.50^{\mathrm{A}}$ & 12.867 & 0.038 \\
ACE & $418.86^{\mathrm{A}}$ & $356.34^{\mathrm{B}}$ & $404.77^{\mathrm{A}}$ & 3.713 & 0.001 \\
Chao & $407.55^{\mathrm{A}}$ & $354.18^{\mathrm{B}}$ & $408.35^{\mathrm{A}}$ & 5.753 & 0.019 \\
Shannon & $2.69^{\mathrm{A}}$ & $2.56^{\mathrm{A}}$ & 2.64 & 0.194 & 0.931 \\
Simpson & 0.16 & $0.14^{4}$ & 0.17 & 0.025 & 0.748 \\
\hline
\end{tabular}

$\overline{\mathrm{A}, \mathrm{B}}$ Means within the same row not followed by the same letters are significantly different at $p \leq 0.05$, whereas the differences were considered to be a statistical trend when $0.05<p \leq 0.10$. CON: basal diet; LNO: basal diet added with flaxseed oil; HLS: basal diet added with heated flaxseed grain. SEM: standard error of the mean. Sobs: the number of OTUs; ACE: the ACE estimator; Chao: the Chao estimator. 


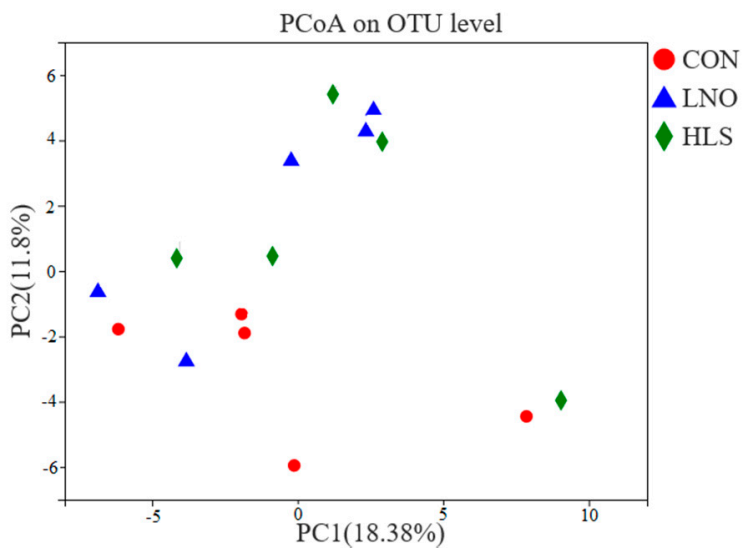

Figure 2. Principal coordinate analysis (PCoA) (using the weighted Unifrac similarity metric) of bacterial operational taxonomic units (OTUs) in the ileum digesta of goat kids. Each symbol represents one treatment: The solid red circle represents kids fed the basal diet (CON), the solid blue triangle represents kids fed the basal diet supplemented with flaxseed oil (LNO), and the solid green rhombus represents kids fed the basal diet supplemented with heated flaxseed grain (HLS).

A total of 698 OTUs were obtained from all samples, of which 402 exist in all groups defined as core OTUs (Figure 3). The core OTUs comprised approximately $57.6 \%$ of the total OTUs. In addition, 25, 38, and 54 OTUs were uniquely identified in groups CON, LNO, and HLS, respectively.

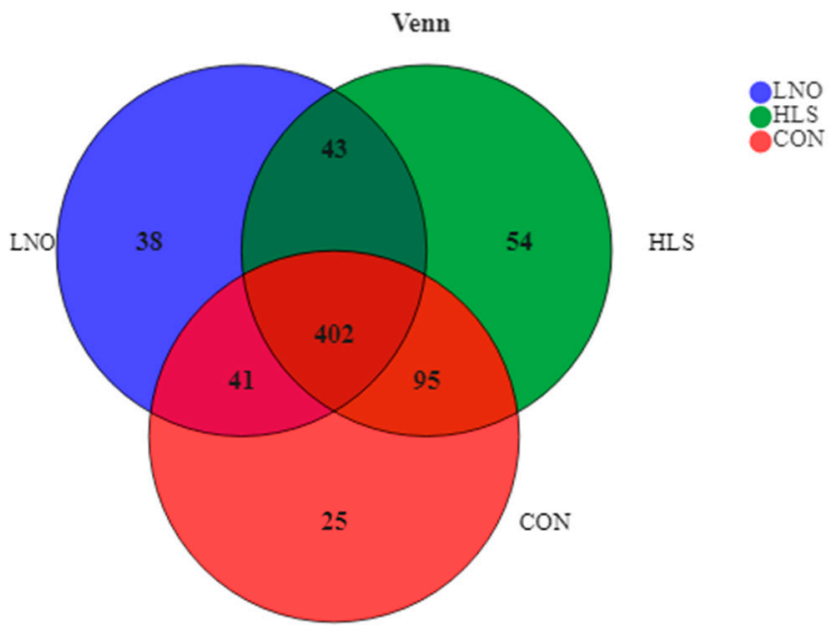

Figure 3. Venn plot of operational taxonomic units (OTUs) showing the percent of observations for each OTU (>0.5\%) present in each dietary group (flaxseed oil, LNO, heated flaxseed grain, HLS, $\mathrm{CON})$. Each color represents one treatment: The red represents kids fed the basal diet (CON), the blue represents kids fed the basal diet supplemented with flaxseed oil (LNO), and the green represents kids fed the basal diet supplemented with heated flaxseed grain (HLS).

\subsubsection{Bacterial Community at Different Taxonomical Levels}

Taxonomic assignment of OTUs identified 17 phyla in the ileum digesta of Albas cashmere goats. As shown in Table 8, a detailed overview of bacteria composition of ileum digesta in each group was illustrated at the phylum level. The Firmicutes is the most predominant phylum in the ileum digesta of the CON (90.80\%), LNO (87.22\%), and HLS (75.83\%) groups, whereas Actinobacteria (CON: $4.96 \%$, LNO: $8.92 \%$, HLS: $20.06 \%$ ) is secondary, they account for $95.76 \%, 96.14 \%$, and $95.89 \%$ of total sequences, respectively. Compared with the CON and LNO groups, the relative abundance (RA) of Firmicutes, Proteobacteria, and Tenericutes reduced remarkably in the HLS group $(p=0.015, p=0.042$, 
$p=0.005)$, the Actinobacteria RA showed the opposite result $(p=0.001)$, and the LNO group did not differ from the CON group.

Table 8. The effect of dietary flaxseed oil or flaxseed supplementation on the relative abundance of bacteria in ileum digesta-Phylum level (\%).

\begin{tabular}{cccccc}
\hline Phylum & CON & LNO & HLS & SEM & $p$-Value \\
\hline Firmicutes & $90.80^{\mathrm{A}}$ & $87.22^{\mathrm{A}}$ & $75.83^{\mathrm{B}}$ & 1.826 & 0.015 \\
Actinobacteria & $4.96^{\mathrm{B}}$ & $8.92^{\mathrm{B}}$ & $20.06^{\mathrm{A}}$ & 1.449 & 0.001 \\
Proteobacteria & $0.79^{\mathrm{A}}$ & $0.71^{\mathrm{A}}$ & $0.37^{\mathrm{B}}$ & 0.106 & 0.042 \\
Tenericutes & $1.25^{\mathrm{A}}$ & $1.03^{\mathrm{A}}$ & $0.62^{\mathrm{B}}$ & 0.102 & 0.005 \\
Bacteroidetes & 1.48 & $1.49^{-}$ & 2.78 & 0.641 & 0.292 \\
others & 0.70 & $0.67^{-}$ & 0.42 & 0.237 & 0.776 \\
\hline
\end{tabular}

$\overline{\mathrm{A}, \mathrm{B}}$ Means within the same row not followed by the same letters are significantly different at $p \leq 0.05$, whereas the differences were considered to be a statistical trend when $0.05<p \leq 0.10$. CON: basal diet; LNO: basal diet added with flaxseed oil; HLS: basal diet added with heated flaxseed grain. SEM: standard error of the mean.

On the genus level, a total of 43 genera were identified from all samples. The 20 most abundant genera are listed in Table 9 for ileum samples. The RA of the top 20 bacterial genera were $73.08 \%, 84.88 \%$, and $66.38 \%$ in the CON, LNO, and HLS groups, respectively. Compared with CON treatment, the RA of unclassified_f_Peptostreptococcaceae (Uncl. Pep.), Clostridium_sensu_stricto_1, and Lachnospiraceae_NK3A20_group significantly decreased in LNO and HLS treatments, and these genera were remarkably lower in the HLS group than in the LNO group $(p<0.0001)$, but the [Eubacterium]_coprostanoligenes_group ([E.] cop. group), Family_XIII_AD3011_group, and Aeriscardovia showed the opposite result $(p<0.0001)$. Compared with CON and LNO treatments, the RA of Intestinibacter remarkably decreased in HLS treatment $(p=0.001)$, but there was no difference between CON and LNO groups. Compared with CON treatment, the RA of Ruminococcus_2, Ruminococcaceae_UCG-014, and Christensenellaceae_R-7_group significantly increased in the LNO group, but these genera remarkably decreased in the HLS group $(p<0.0001)$. Compared with CON and HLS treatments, the Turicibacter RA remarkably increased in LNO treatment $(p<0.0001)$, the Streptococcus and [Ruminococcus]_gauvreauii_group showed the opposite result, and there was no difference between CON and HLS groups. Compared with CON treatment, the RA of Lactobacillus, Bifidobacterium, Olsenella, and Ureaplasma significantly increased in LNO and HLS treatments, and these genera were remarkably higher in LNO treatment than in HLS treatment $(p<0.0001)$. Compared with $\mathrm{CON}$ treatment, the RA of Acetitomaculum and Mycoplasma significantly decreased in LNO and HLS treatments, and these genera were remarkably lower in the LNO group than in the HLS group $(p<0.0001)$. The unclassified_f_Bifidobacteriaceae RA tended to be remarkably lower in the HLS group than in the CON group $(p=0.064)$, but the LNO group did not differ from the CON and HLS groups. 
Table 9. The effect of dietary flaxseed oil or heated flaxseed supplementation on the relative abundance of the top 20 bacteria in ileum digesta-Genus level (\%).

\begin{tabular}{|c|c|c|c|c|c|c|}
\hline Family & Genus & CON & LNO & HLS & SEM & $p$-Value \\
\hline \multicolumn{7}{|l|}{ Phylum-Firmicutes } \\
\hline Peptostreptococcaceae & g__unclassified_f__Peptostreptococcaceae & $35.14^{\mathrm{A}}$ & $31.22 \mathrm{~B}$ & $13.13^{\mathrm{C}}$ & 0.610 & $<0.0001$ \\
\hline Peptostreptococcaceae & g__Intestinibacter & $13.73^{\mathrm{A}}$ & $12.01 \mathrm{~A}$ & $9.32^{\mathrm{B}}$ & 0.615 & 0.001 \\
\hline Clostridiaceae_1 & g_Clostridium_sensu_stricto_1 & $4.13^{\mathrm{A}}$ & $2.03 \mathrm{~B}$ & $1.83^{\mathrm{C}}$ & 0.055 & $<0.0001$ \\
\hline Ruminococcaceae & g_Ruminococcus_2 & $3.32^{\mathrm{B}}$ & $10.61 \mathrm{~A}$ & $0.42^{\mathrm{C}}$ & 0.561 & $<0.0001$ \\
\hline Lachnospiraceae & g_Lachnospiraceae_NK3A20_group & $2.58^{\mathrm{A}}$ & $1.94 \mathrm{~B}$ & $1.46^{\mathrm{C}}$ & 0.104 & $<0.0001$ \\
\hline Ruminococcaceae & g_[Eubacterium]_coprostanoligenes_group & $2.54^{\mathrm{C}}$ & $4.89^{\mathrm{B}}$ & $16.92^{\mathrm{A}}$ & 0.598 & $<0.0001$ \\
\hline Erysipelotrichaceae & g_turicibacter & $1.63^{\mathrm{B}}$ & $2.84^{\mathrm{A}}$ & $1.58^{\mathrm{B}}$ & 0.095 & $<0.0001$ \\
\hline Ruminococcaceae & g__Ruminococcaceae_UCG-014 & $1.51^{\mathrm{B}}$ & $4.10^{\mathrm{A}}$ & $0.12^{\mathrm{C}}$ & 0.204 & $<0.0001$ \\
\hline Lachnospiraceae & g_Acetitomaculum & $1.43^{\mathrm{A}}$ & $0.32^{\mathrm{C}}$ & $0.66^{\mathrm{B}}$ & 0.092 & $<0.0001$ \\
\hline Christensenellaceae & g_Christensenellaceae_R-7_group & $1.34^{\mathrm{B}}$ & $4.72^{\mathrm{A}}$ & $0.61^{\mathrm{C}}$ & 0.052 & $<0.0001$ \\
\hline Family_XIII & g_Family_XIII_AD3011_group & $0.81^{\mathrm{C}}$ & $1.07^{\mathrm{B}}$ & $1.59^{\mathrm{A}}$ & 0.078 & $<0.0001$ \\
\hline Streptococcaceae & g_Streptococcus & $0.74^{\mathrm{A}}$ & $0.36^{\mathrm{B}}$ & $0.74^{\mathrm{A}}$ & 0.036 & $<0.0001$ \\
\hline Lachnospiraceae & g_[Ruminococcus]_gauvreauii_group & $0.61^{\mathrm{A}}$ & $0.13^{\mathrm{B}}$ & $0.61^{\mathrm{A}}$ & 0.058 & $<0.0001$ \\
\hline Lactobacillaceae & g_L_Lactobacillus & $0.05^{\mathrm{C}}$ & $0.88^{\mathrm{A}}$ & $0.22^{\mathrm{B}}$ & 0.036 & $<0.0001$ \\
\hline \multicolumn{7}{|l|}{ Phylum-Actinobacteria } \\
\hline Bifidobacteriaceae & g__Aeriscardovia & $2.08^{\mathrm{C}}$ & $3.13^{\mathrm{B}}$ & $14.95^{\mathrm{A}}$ & 0.325 & $<0.0001$ \\
\hline Bifidobacteriaceae & g_Bifidobacterium & $0.27^{\mathrm{C}}$ & $0.41^{\mathrm{A}}$ & $0.32^{\mathrm{B}}$ & 0.012 & $<0.0001$ \\
\hline Bifidobacteriaceae & g__unclassified_f__Bifidobacteriaceae & 0.26 & 0.23 & 0.17 & 0.025 & 0.064 \\
\hline Coriobacteriaceae & g__Olsenella & $0.16^{\mathrm{C}}$ & $3.73^{\mathrm{A}}$ & $1.26^{\mathrm{B}}$ & 0.028 & $<0.0001$ \\
\hline \multicolumn{7}{|l|}{ Phylum-Tenericutes } \\
\hline Mycoplasmataceae & g__Mycoplasma & $0.73^{\mathrm{A}}$ & $0.21^{\mathrm{C}}$ & $0.44^{\mathrm{B}}$ & 0.036 & $<0.0001$ \\
\hline Mycoplasmataceae; & g_Ureaplasma & $0.02^{\mathrm{C}}$ & $0.05^{\mathrm{A}}$ & $0.03^{\mathrm{B}}$ & 0.002 & $<0.0001$ \\
\hline
\end{tabular}

A-C Means within the same row not followed by the same letters are significantly different at $p \leq 0.05$, whereas the differences were considered to be a statistical trend when $0.05<p \leq 0.10$. CON: basal diet; LNO: basal diet added with flaxseed oil; HLS: basal diet added with heated flaxseed grain. SEM: standard error of the mean.

\subsubsection{Spearman Correlation Analysis}

Spearman correlation analysis was conducted between the abundance of the top 20 bacterial genera and growth performance, fat tissue, blood lipid profiles, and the enzymes related to blood lipid metabolism, as indicated in Tables 10-12. The threshold $|\mathrm{R}|>0.5$ and $p \leq 0.05$ is considered as a significant Spearman correlation. The [Ruminococcus]_gauvreauii_group was significantly positively correlated with BHBA and NEFA, but negatively associated with BWG, Omental Fat, and GLU. The Streptococcus was positively correlated with BHBA and NEFA, but negatively associated with FBW, BWG, Omental Fat, Kidney Fat, GLU, ACC, FAS, and MDH. The Turicibacter was positively correlated with FBW, BWG, Omental Fat, $\mathrm{CHO}, \mathrm{ACC}$, and FAS, but negatively associated with BHBA and NEFA. The Acetitomaculum and Mycoplasma were negatively associated with BWG, Omental Fat, GLU, HDL-C, and ACC. The Bifidobacterium was positively correlated with BWG, Omental Fat, Mesenteric Fat, GLU, HDL-C, and ACC, but negatively associated with BHBA and NEFA. The Christensenellaceae_R-7_group was positively correlated with BWG, Omental Fat, $\mathrm{CHO}$, LDL-C, and ACC, but negatively associated with BHBA, NEFA, and HSL. The Olsenella was positively correlated with BWG and GLU. The Ruminococcaceae_UCG-014 was positively correlated with BWG, Omental Fat, CHO, LDL-C, ACC, and MDH, but negatively associated with BHBA, NEFA, and HSL. The Ruminococcus_2 was positively correlated with FBW, BWG, Omental Fat, GLU, CHO, LDL-C ACC, FAS, and MDH, but negatively associated with BHBA, NEFA, and HSL. The Ureaplasma was positively correlated with BWG, Omental Fat, and GLU, but negatively associated with NEFA. The Lactobacillus was positively correlated with GLU. The Lachnospiraceae_NK3A20_group was positively correlated with TG and LDL-C, but negatively associated with HSL. The Intestinibacter was positively correlated with MDH, but negatively associated with BHBA and NEFA. The Family_XIII_AD3011_group was positively correlated with HSL, but negatively associated with LDL-C. The Clostrid- 
ium_sensu_stricto_1 was positively correlated with LDL-C, but negatively associated with HSL. The unclassified_f__Bifidobacteriaceae was negatively associated with HDL-C. The Aeriscardovia was positively correlated with HSL, but negatively associated with LDL-C. The Uncl. Pep. Was negatively associated with HSL and LPL, but the [E.] cop. group was positively correlated with them.

Table 10. Growth performance and lipid deposition showing a Spearman's correlation with ileal bacterial community.

\begin{tabular}{|c|c|c|c|c|c|c|c|c|c|c|}
\hline \multirow{2}{*}{ Items } & \multicolumn{2}{|c|}{ FBW } & \multicolumn{2}{|c|}{ BWG } & \multicolumn{2}{|c|}{ Omental Fat } & \multicolumn{2}{|c|}{ Kidney Fat } & \multicolumn{2}{|c|}{ Mesenteric Fat } \\
\hline & $\mathbf{R}^{(1)}$ & $p$-Value ${ }^{(2)}$ & $\mathbf{R}$ & $p$-Value & $\mathbf{R}$ & $p$-Value & $\mathbf{R}$ & $p$-Value & $\mathbf{R}$ & $p$-Value \\
\hline $\begin{array}{l}\text { g_[Ruminococcus] } \\
\text { _gauvreauii_group }\end{array}$ & & & -0.52 & 0.04 & -0.72 & 0.002 & & & & \\
\hline $\mathrm{g}$ Streptococcus & -0.55 & 0.04 & -0.64 & 0.01 & -0.82 & 0.0002 & -0.52 & 0.05 & & \\
\hline g__Turicibacter & 0.58 & 0.02 & 0.73 & 0.002 & 0.74 & 0.001 & & & & \\
\hline g_Acetitomaculum & & & -0.64 & 0.01 & -0.59 & 0.02 & & & & \\
\hline g_Bifidobacterium & & & 0.77 & 0.001 & 0.63 & 0.01 & & & 0.62 & 0.01 \\
\hline $\begin{array}{l}\text { g__Christensenellaceae } \\
\text { R-7_group }\end{array}$ & & & 0.66 & 0.01 & 0.81 & 0.0002 & & & & \\
\hline g__Mycoplasma & & & -0.61 & 0.02 & -0.52 & 0.05 & & & & \\
\hline g__Olsenella & & & 0.60 & 0.02 & & & & & & \\
\hline $\begin{array}{l}\text { g__Ruminococcaceae } \\
\text { _UCG-014 }\end{array}$ & & & 0.54 & 0.04 & 0.83 & 0.0001 & & & & \\
\hline $\bar{g} \_$Ruminococcus_2 & 0.53 & 0.04 & 0.62 & 0.01 & 0.88 & $<0.0001$ & & & & \\
\hline g_Ureaplasma & & & 0.58 & 0.02 & 0.54 & 0.04 & & & & \\
\hline
\end{tabular}

(1) Spearman correlation coefficient (R) represents the degree of association between ileum bacterial community and growth performance, lipid deposition. ${ }^{(2)}$ Correlations with $p \leq 0.05$ for the linear model were considered as significant. FBW: final body weight; BWG: total body weight gain. 
Table 11. Blood lipid profiles showing a Spearman's correlation with ileal bacterial community.

\begin{tabular}{|c|c|c|c|c|c|c|c|c|c|c|c|c|c|c|}
\hline \multirow{2}{*}{ Items } & \multicolumn{2}{|c|}{ GLU } & \multicolumn{2}{|c|}{ BHBA } & \multicolumn{2}{|c|}{ NEFA } & \multicolumn{2}{|c|}{ TG } & \multicolumn{2}{|c|}{$\mathrm{CHO}$} & \multicolumn{2}{|c|}{ LDL-C } & \multicolumn{2}{|c|}{ HDL-C } \\
\hline & $R^{(1)}$ & $p$-Value ${ }^{(2)}$ & $\mathbf{R}$ & $p$-Value & $\mathbf{R}$ & $p$-Value & $\mathbf{R}$ & $p$-Value & $\mathbf{R}$ & $p$-Value & $\mathbf{R}$ & $p$-Value & $\mathbf{R}$ & $p$-Value \\
\hline g_[Ruminococcus]_gauvreauii_group & -0.57 & 0.03 & 0.64 & 0.01 & 0.71 & 0.003 & & & & & & & & \\
\hline g_Streptococcus & -0.57 & 0.03 & 0.78 & 0.0006 & 0.71 & 0.003 & & & & & & & & \\
\hline g_Acetitomaculum & -0.71 & 0.003 & & & & & & & & & & & -0.55 & 0.03 \\
\hline g_Bifidobacterium & 0.55 & 0.03 & -0.54 & 0.04 & -0.62 & 0.01 & & & & & & & 0.60 & 0.02 \\
\hline g_Christensenellaceae_R-7_group & & & -0.88 & $<0.0001$ & -0.94 & $<0.0001$ & & & 0.69 & 0.005 & 0.73 & 0.002 & & \\
\hline g_Mycoplasma & -0.56 & 0.03 & & & & & & & & & & & -0.56 & 0.03 \\
\hline g_Olsenella & 0.59 & 0.02 & & & & & & & & & & & & \\
\hline g_Ruminococcus_2 & 0.52 & 0.05 & -0.92 & $<0.0001$ & -0.88 & $<0.0001$ & & & 0.63 & 0.01 & 0.52 & 0.05 & & \\
\hline g_Ureaplasma & 0.55 & 0.03 & & & -0.55 & 0.03 & & & & & & & & \\
\hline g_Lactobacillus & 0.60 & 0.02 & & & & & & & & & & & & \\
\hline g_Lachnospiraceae_NK3A20_group & & & & & & & 0.53 & 0.04 & & & 0.64 & 0.01 & & \\
\hline g_Intestinibacter & & & -0.63 & 0.01 & -0.55 & 0.03 & & & & & & & & \\
\hline g_Family_XIII_AD3011_group & & & & & & & & & & & -0.62 & 0.01 & & \\
\hline g_Clostridium_sensu_stricto_1 & & & & & & & & & & & 0.58 & 0.02 & & \\
\hline g_unclassified_f_Bifidobacteriaceae & & & & & & & & & & & & & -0.65 & 0.01 \\
\hline g_Aeriscardovia & & & & & & & & & & & -0.55 & 0.03 & & \\
\hline
\end{tabular}

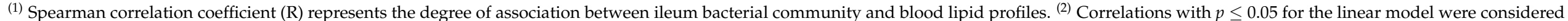

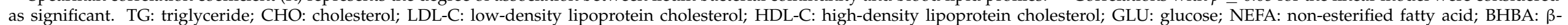
hydroxybutyric acid. 
Table 12. The enzymes related to blood lipid metabolism showing a Spearman's correlation with ileal bacterial community.

\begin{tabular}{|c|c|c|c|c|c|c|c|c|c|c|}
\hline \multirow{2}{*}{ Items } & \multicolumn{2}{|c|}{$\mathrm{ACC}$} & \multicolumn{2}{|c|}{ FAS } & \multicolumn{2}{|c|}{ HSL } & \multicolumn{2}{|c|}{ LPL } & \multicolumn{2}{|c|}{ MDH } \\
\hline & $\mathbf{R}^{(1)}$ & $p$-Value ${ }^{(2)}$ & $\mathbf{R}$ & $p$-Value & $\mathbf{R}$ & $p$-Value & $\mathbf{R}$ & $p$-Value & $\mathbf{R}$ & $p$-Value \\
\hline g_Streptococcus & -0.56 & 0.03 & -0.64 & 0.01 & & & & & -0.78 & 0.001 \\
\hline g_Turicibacter & 0.71 & 0.003 & 0.52 & 0.04 & & & & & & \\
\hline g_Acetitomaculum & -0.60 & 0.02 & & & & & & & & \\
\hline g_Bifidobacterium & 0.60 & 0.02 & & & & & & & & \\
\hline g_Christensenellaceae_R-7_group & 0.59 & 0.02 & & & -0.70 & 0.004 & & & & \\
\hline g___Mycoplasma & -0.52 & 0.05 & & & & & & & & \\
\hline g_Ruminococcaceae_UCG-014 & 0.57 & 0.03 & & & -0.53 & 0.04 & & & 0.57 & 0.03 \\
\hline g_Ruminococcus_2 & 0.57 & 0.03 & 0.54 & 0.04 & -0.52 & 0.05 & & & 0.67 & 0.01 \\
\hline g_Lachnospiraceae_NK3A20_group & & & & & -0.78 & 0.001 & & & & \\
\hline g__Intestinibacter & & & & & & & & & 0.51 & 0.05 \\
\hline g_Family_XIII_AD3011_group & & & & & 0.78 & 0.001 & & & & \\
\hline g_Clostridium_sensu_stricto_1 & & & & & -0.77 & 0.001 & & & & \\
\hline g_unclassified_f_Peptostreptococcaceae & & & & & -0.67 & 0.01 & -0.56 & 0.03 & & \\
\hline g_[Eubacterium]_coprostanoligenes_group & & & & & 0.71 & 0.003 & 0.56 & 0.03 & & \\
\hline g_Aeriscardovia & & & & & 0.75 & 0.001 & & & & \\
\hline
\end{tabular}

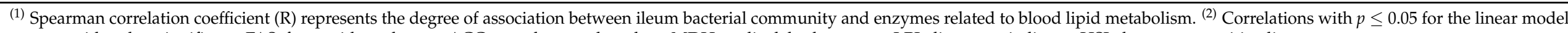
were considered as significant. FAS: fatty acid synthetase; ACC: acetyl-coa carboxylase; MDH: malic dehydrogenase; LPL: lipo-protein lipase; HSL: hormone-sensitive lipase. 


\section{Discussion}

Our previous study has shown that, compared with the addition of flaxseed oil, flaxseed could protect ALA from the hydrogenation in rumen, increase the ALA content in blood, and then increase the ALA accumulation in muscle of goats, which is beneficial to human health $[10,17]$. However, the comparison effects of flaxseed oil and flaxseed grain on lipid deposition and ileum microbiota profiles have not been investigated. The present study indicated that flaxseed is more effective than flaxseed oil in reducing lipid deposition, which may work by modulating the ileal microbiota composition.

Candyrine et al. reported that $4 \%$ oil supplementation to diet significantly enhanced the growth performance in fattening sheep and goats [22]. In the current study, compared with the CON group, the dietary flaxseed oil supplementation significantly increased the FBW and BWG, which agrees with the above report. Compared with the CON treatment, flaxseed oil significantly promoted the FBW, BWG, and lipid accumulation in goats, but the dietary flaxseed supplementation had no effect on the growth performance of goats. However, compared with the LNO group, the dietary flaxseed supplementation reduced the adipose tissue weight, indicating that flaxseed efficiently reduced the lipid deposition of goats. Blood biochemical parameters can reflect the physiological and metabolic state of animals, which is closely related to nutritional status. The present results showed that the dietary flaxseed grain supplementation significantly decreased the content of TG, $\mathrm{CHO}$, and LDL-C in serum, indicating that flaxseed could reduce the blood lipid deposition, which is consistent with the results of changes in adipose tissue weight. In agreement with these findings, the majority of previous studies showed that flaxseed consumption reduced serum content of $\mathrm{CHO}$ [23] and LDL-C [24] levels. In the current study, compared with the CON and HLS groups, the flaxseed oil had a tendency to increase the serum GLU content and significantly reduced the serum BHBA content, which suggested that the addition of flaxseed oil to the diet reduced lipid mobilization, resulting in an increase of lipid deposition. Compared with the LNO group, flaxseed significantly increased the serum BHBA and NEFA content, which indicated that cashmere goats would mobilize lipid to meet growth needs, so they produced a large amount of BHBA and NEFA. ACC and FAS are the key enzymes involved in de novo FA synthesis and play a key role in animal lipid synthesis [10]. MDH is closely involved in the trans hydrogenation during the conversion of carbohydrates to fatty acids [25]. HSL is the key enzyme and rate-limiting enzyme that initially mobilized lipolysis, it gradually hydrolyzes the fat stored in fat cells into free FA and glycerin and releases them into the blood [26]. In the current study, compared with the LNO treatment, the flaxseed grain significantly decreased the quantity of FAS, ACC, and $\mathrm{MDH}$, but remarkably promoted the HSL quantity. These results suggested that adding flaxseed grain to the diet could reduce the quantity of enzymes related to lipid de novo synthesis and increase the quantity of enzymes related to lipolysis, thereby reducing the blood TG content and TG accumulation in the adipose tissue, which further explained the above-mentioned change of growth performance and lipid deposition. Liu et al. reported that the diets containing unsaturated fatty acids (UFAs) could reduce serum $\mathrm{CHO}$, TG, and LDL-C content, but increase serum HDL-C content [27]. Egert et al. observed that enrichment of the diet with EPA or DHA decreased fasting serum TG concentration by $15 \%$ and $31 \%$ in humans, suggesting that DHA is more effective in reducing TG levels in the blood [28]. Morin et al. reported a lower serum CHO and LDL-C levels of rats in the DHA monoglycerides treatment than the high-fat/high-carbohydrate diet [29]. In our previous study, the flaxseed grain group had a higher plasma concentration of DHA than the control and supplemented flaxseed oil groups [10], but in the present study, had a lower serum TG, $\mathrm{CHO}$, and LDL-C content, hinting that flaxseed grain is more efficient to goats in reducing the blood TG, CHO, and LDL-C level because of the decreased plasma DHA. Sawada et al. reported that the EPA significantly improved the HDL-C concentration in blood of humans [30]. HDL-C removes cholesterol from the bloodstream and carries it back to the liver for recycling [31], which is beneficial to the health of livestock. In the present study, the diet supplemented with flaxseed oil and flaxseed grain had a tendency to increase the serum 
HDL-C concentration compared to the CON group, which probably related to the increase of plasma EPA concentration [10]. Some researches indicated that the lipid-lowering effect of flaxseed is owing to its high content of lignans and soluble fibers [32,33]. Lignans are one of the vital groups of phytoestrogens, which inhibit acyl-coenzyme A activity: $\mathrm{CHO}$ acyltransferase involved in the formation of cholesteryl ester in tissues [34,35]. Soluble fibers can reduce intestinal absorption of dietary $\mathrm{CHO}$ and increase the production of bile acid [33]. In conclusion, supplementation of flaxseed significantly alleviated the lipid accumulation in goats compared to the addition of flaxseed oil, indicating that flaxseed (enriched ALA) may play an important role in regulating lipid metabolism, and therefore it is beneficial to the goats.

In recent years, the gut microbiota has been shown to affect lipid levels and lipid metabolism in blood. In the present study, the dietary flaxseed supplementation significantly reduced the relative abundance of Firmicutes, Proteobacteria, and Tenericutes, while it remarkably increased the Actinobacteria relative abundance. Firmicutes is known as obesity-related bacterial phylum, which accelerates degradation of food components to supply energy for the host [36]. A high abundance of Firmicutes goes with a low abundance of Bacteroidetes, which leads to accelerate energy harvest from food and promote energy storage in adipose tissue of the host [37] and would further suppress the fasting-induced adipose factor (FIAF) produced. Meanwhile, a higher TG was stored in adipose tissue and lower satiety hormones were released by the suppression of FIAF [38]. In the current study, the dietary flaxseed significantly decreased the Firmicutes relative abundance compared to the CON and LNO groups, so we speculated that adding flaxseed to the diet promoted the production of FIAF by reducing the Firmicutes relative abundance, thereby releasing more satiety hormones, reducing the absorption of energy from the diet through ileum, which further explained the decrease in blood TG and fat tissue weight. Proteobacteria is a major phylum of Gram-negative bacteria with a wide range of pathogenic microorganisms, and a high ratio of Proteobacteria to Firmicutes + Bacteroidetes was confirmed as a good indicator for rumen dysbiosis [39]. The addition of flaxseed decreased the Proteobacteria relative abundance in ileum of goats, which may be caused by competitive relationships between the gut microbiota and pathogenic bacteria in the intestine [40], indicating that the flaxseed is beneficial to the colonization of probiotic in the goats' ileum. Actinobacteria is the dominant bacterial in most mammals [41]. In the long-term co-evolution process of animal intestinal Actinobacteria and the host, by producing a variety of bioactive substances, such as antibiotics, immunosuppressants, vitamins, and enzymes, they participate in the metabolism of the host and maintain the intestinal microecological balance of the host and a series of important physiological activities [42]. Claus et al. reported that the Actinobacteria was negatively associated with serum GLU level in the microbial colonization process [43]. The current study observed that, compared to added flaxseed oil, dietary flaxseed supplementation increased the Actinobacteria relative abundance and had a tendency to reduce the serum GLU content, which is similar to the above-mentioned reports.

[E.] cop. is a CHO-reducing bacterium, and on the one hand, converting $\mathrm{CHO}$ to coprostanol could decrease the $\mathrm{CHO}$ absorption [44]. On the other hand, the bacterium might interrupt the enterohepatic circulation of billary $\mathrm{CHO}$ so that the liver would partition more $\mathrm{CHO}$ into the bile and less $\mathrm{CHO}$ into the blood [45]. In the current study, [E.] cop. group (16.92\%), Aeriscardovia (14.95\%), and Uncl. Pep. (13.13\%) were the 3 most abundant genera in the goats' ileum of the HLS group, which showed that the flaxseed significantly increased the [E.] cop. group relative abundance and remarkably decreased the blood CHO content, and that the [E.] cop. group was positively correlated with the content of HSL and LPL, illustrating that the flaxseed can reduce the absorption of $\mathrm{CHO}$ in ileum and increase the degradation of lipid by increasing the relative abundance of [E.] cop. group. Whon et al. reported that the castrated male cattle harbor distinct ileum microbiota which were dominated by the family Peptostreptococcaceae, with increased extra- and intra-muscular fat storage [46]. A previous study revealed that the Uncl. Pep. might play an important role in feed digestion [47]. In the current study, Uncl. Pep. (31.22\%), Intestinibacter (12.01\%), 
and Ruminococcus_2 (10.61\%) were the 3 most abundant genera in the goats' ileum of the LNO group, Uncl. Pep. (35.14\%) and Intestinibacter (13.73\%) were the 2 most abundant genera in the goats' ileum of the CON group, the relative abundance of Uncl. Pep. and Intestinibacter are significantly higher in the CON and LNO groups than in the HLS group, and the blood TG content showed a consistent trend of change. Meanwhile, the current results showed that the Uncl. Pep. was negatively associated with the quantity of HSL and $\mathrm{LPL}$, and the Intestinibacter was negatively associated with the content of BHBA and NEFA. These results hinted that the increased absorption of nutrients in ileum and the reduced mobilization of body fat in goats of CON and LNO groups was due to increasing the relative abundance of Uncl. Pep. and Intestinibacter. Jiang et al. reported that the increase of Ruminococcus relative abundance can increase the digestibility of DM and NDF in vivo and the production performance of cows [48]. The dietary supplementation of flaxseed oil significantly elevated the Ruminococcus_2 relative abundance and increased the FBW and BWG of goats, and the Ruminococcus_2 genus was positively associated with FBW, BWG, Omental Fat, GLU, CHO, LDL-C, ACC, and MDH, but negatively correlated with BHBA, NEFA, and HSL. Therefore, these results hinted that the flaxseed oil can promote the absorption of nutrients and reduce lipid mobilization, leading to much more GLU and TG flowed into blood, more lipid deposition in adipose tissue, and increasing the FBW of goats by increasing the Ruminococcus_2 relative abundance.

The present study investigated the shift among blood lipid profiles in cashmere goats in response to dietary supplementation of flaxseed or flaxseed oil, which probably related to the change of ileal microbial composition, but the mechanism is unclear. Therefore, the ileal metabolites of goats fed a diet containing flaxseed or flaxseed oil needed to be measured to further elucidate the mechanism in the future. The [E.] cop. is the most relatively abundant genus in the ileum of HLS goats and the Ruminococcus_2 is the third top genus in the ileum of LNO goats, and they are strongly associated with host lipid metabolism, so the function of [E.] cop. and Ruminococcus_2 on lipid metabolism needed to be verified in vitro. In addition, further study is needed to test other intestinal microbes (duodenum, jejunum, cecum, and colon), to better interpret the microbiota compositions and the shift of microbiota in response to dietary supplementation of flaxseed or flaxseed oil.

\section{Conclusions}

In conclusion, the flaxseed grain is more efficient than flaxseed oil in ameliorating the blood lipid profiles and it is a potential product in decreasing the lipid deposition of cashmere goats. The blood lipid profiles in cashmere goats in response to dietary supplementation of flaxseed or flaxseed oil are probably related to the change of the ileal microbiota composition.

Author Contributions: S.L. was involved in the animal experimentation, sample analysis, data interpretation and writing original draft. X.W. was involved in the animal experimentation, sample analysis. Y.L. was involved in the animal experimentation. B.S. was involved in the sample collection and data interpretation. X.G. and Y.Z. were involved in the sample collection and data analysis. S.Y. was involved in the project administration, study design and writing-review and editing. All authors have read and agreed to the published version of the manuscript.

Funding: This work was supported by grants of the National Natural Science Foundation of China (Project No. 31760685) and the National Key R\&D Program of China (Project No. 2017YFD0500504).

Institutional Review Board Statement: The experiment was conducted in the experimental farm of Inner Mongolia Agricultural University (Hohhot, China). All animal procedures were performed under the national standard Guidelines for Ethical Review of Animal Welfare (GB/T 35892-2018).

Data Availability Statement: The raw data presented in the current study are available on reasonable request from the corresponding author.

Acknowledgments: For their help during laboratory and data analysis, the authors express deep appreciation to Qi Wen, Yongsheng Zhang, and Siqingaowa Bao from College of Animal Science, Inner Mongolia Agricultural University, China. 
Conflicts of Interest: There is no potential conflict of interest among the authors.

\section{References}

1. Song, S.; Wu, J.; Zhao, S.; Casper, D.P.; Zhang, L.; He, B.; Lang, X.; Wang, C.; Gong, X.; Wang, F.; et al. The effect of periodic energy restriction on growth performance, serum biochemical indices, and meat quality in sheep. J. Anim. Sci. 2018, 96, 4251-4263. [CrossRef]

2. Habibizad, J.; Riasi, A.; Kohram, H.; Rahmani, H.R. Effect of feeding greater amounts of dietary energy for a short-term with or without eCG injection on reproductive performance, serum metabolites and hormones in ewes. Anim. Reprod. Sci. 2015, 160, 82-89. [CrossRef]

3. Chen, G.J.; Song, S.D.; Wang, B.X.; Zhang, Z.F.; Peng, Z.L.; Guo, C.H.; Zhong, J.C.; Wang, Y. Effects of Forage:Concentrate Ratio on Growth Performance, Ruminal Fermentation and Blood Metabolites in Housing-feeding Yaks. Asian-Australas. J. Anim. Sci. 2015, 28, 1736-1741. [CrossRef]

4. Bauchart, D. Lipid absorption and transport in ruminants. J. Dairy Sci. 1993, 76, 3864-3881. [CrossRef]

5. Prasad, K. Flaxseed and cardiovascular health. J. Cardiovasc. Pharmacol. 2009, 54, 369-377. [CrossRef]

6. Flaxseed oil: Healthful or harmful for men? Harv. Men's Health Watch 2003, 8, 5-8.

7. Shah, M.; Eklund, B.; Conde Lima, L.G.; Bergholz, T.; Hall, C. Microbial and Chemical Shelf-Life of Vacuum Steam-Pasteurized Whole Flaxseed and Milled Flaxseed. J. Food Sci. 2018, 83, 300-308. [CrossRef] [PubMed]

8. Petit, H.V.; Dewhurst, R.J.; Proulx, J.G.; Khalid, M.; Haresign, W.; Twagiramungu, H. Milk production, milk composition, and reproductive function of dairy cows fed different fats. Can. J. Anim. Sci. 2001, 81, 263-271. [CrossRef]

9. Liu, A.J.; Zhao, Y.; Zhang, G.R.; Wang, D.; Wang, Y.X. Effects of $\alpha$-Linolenic Acid Calcium on Lipid Metabolism of Mice with Hyperlipidemia. Mod. Food Sci. Technol. 2009, 25, 1144-1145. [CrossRef]

10. Wang, X.; Martin, G.B.; Liu, S.; Shi, B.; Guo, X.; Zhao, Y.; Yan, S. The mechanism through which dietary supplementation with heated linseed grain increases n-3 long-chain polyunsaturated fatty acid concentration in subcutaneous adipose tissue of cashmere kids. J. Anim. Sci. 2019, 97, 385-397. [CrossRef]

11. Yagi, S.; Fukuda, D.; Aihara, K.I.; Akaike, M.; Shimabukuro, M.; Sata, M. n-3 Polyunsaturated Fatty Acids: Promising Nutrients for Preventing Cardiovascular Disease. J. Atheroscler. Thromb. 2017, 24, 999-1010. [CrossRef]

12. Mori, T.A. Dietary n-3 PUFA and CVD: A review of the evidence. Proc. Nutr. Soc. 2014, 73, 57-64. [CrossRef]

13. Fu, J.; Bonder, M.J.; Cenit, M.C.; Tigchelaar, E.F.; Maatman, A.; Dekens, J.A.; Brandsma, E.; Marczynska, J.; Imhann, F.; Weersma, R.K.; et al. The Gut Microbiome Contributes to a Substantial Proportion of the Variation in Blood Lipids. Circ. Res. 2015, 117, 817-824. [CrossRef]

14. Wen, C.; Yan, W.; Sun, C.; Ji, C.; Zhou, Q.; Zhang, D.; Zheng, J.; Yang, N. The gut microbiota is largely independent of host genetics in regulating fat deposition in chickens. ISME J. 2019, 13, 1422-1436. [CrossRef] [PubMed]

15. Huang, X.; Fang, S.; Yang, H.; Gao, J.; He, M.; Ke, S.; Zhao, Y.; Chen, C.; Huang, L. Evaluating the contribution of gut microbiome to the variance of porcine serum glucose and lipid concentration. Sci. Rep. 2017, 7, 14928. [CrossRef]

16. Yang, X.; Yin, F.; Yang, Y.; Lepp, D.; Yu, H.; Ruan, Z.; Yang, C.; Yin, Y.; Hou, Y.; Leeson, S.; et al. Dietary butyrate glycerides modulate intestinal microbiota composition and serum metabolites in broilers. Sci. Rep. 2018, 8, 4940. [CrossRef] [PubMed]

17. Wang, X.; Martin, G.B.; Wen, Q.; Liu, S.; Zhang, J.; Yu, Y.; Shi, B.; Guo, X.; Zhao, Y.; Yan, S. Linseed oil and heated linseed grain supplements have different effects on rumen bacterial community structures and fatty acid profiles in cashmere kids. J. Anim. Sci. 2019, 97, 2099-2113. [CrossRef] [PubMed]

18. Jiao, J.; Huang, J.; Zhou, C.; Tan, Z. Taxonomic Identification of Ruminal Epithelial Bacterial Diversity during Rumen Development in Goats. Appl. Environ. Microbiol. 2015, 81, 3502-3509. [CrossRef]

19. Jiao, J.; Li, X.; Beauchemin, K.A.; Tan, Z.; Tang, S.; Zhou, C. Rumen development process in goats as affected by supplemental feeding v. grazing: Age-related anatomic development, functional achievement and microbial colonisation. Br. J. Nutr. 2015, 113, 888-900. [CrossRef] [PubMed]

20. Yan, Z.; Zeng, D.; Zhang, Y.; Ni, X.Q.; Tang, Y.R.; Zhu, H.; Wang, H.S.; Yin, Z.Q.; Pan, K.C.; Jing, B. Characterization of the cellulolytic bacteria communities along the gastrointestinal tract of Chinese Mongolian sheep by using PCR-DGGE and real-time PCR analysis. World J. Microbiol. Biotechnol. 2015, 31, 1103-1113. [CrossRef]

21. China NY/T816. Feeding Standard of Meat-Producing Sheep and Goats; China NongYe HangYe Biaozhun/Tuijian-816; China Agricultural Publisher: Beijing, China, 2004.

22. Candyrine, S.; Jahromi, M.F.; Ebrahimi, M.; Chen, W.L.; Rezaei, S.; Goh, Y.M.; Abdullah, N.; Liang, J.B. Oil supplementation improved growth and diet digestibility in goats and sheep fed fattening diet. Asian-Australas. J. Anim. Sci. 2019, 32, 533-540. [CrossRef]

23. Haliga, R.E.; Mocanu, V.; Badescu, M. Antioxidative and antiatherogenic effects of flaxseed, $\alpha$-tocopherol and their combination in diabetic hamsters fed with a high-fat diet. Exp. Ther. Med. 2015, 9, 533-538. [CrossRef]

24. Prasad, K.; Jadhav, A. Prevention and treatment of atherosclerosis with flaxseed-derived compound secoisolariciresinol diglucoside. Curr. Pharm. Des. 2016, 22, 214-220. [CrossRef]

25. Bogin, E.; Avidar, Y.; Merom, M.; Soback, S.; Brenner, G. Biochemical changes associated with the fatty liver syndrome in cows. J. Comp. Pathol. 1988, 98, 337-347. [CrossRef] 
26. Bolsoni-Lopes, A.; Alonso-Vale, M.I. Lipolysis and lipases in white adipose tissue-An update. Arch. Endocrinol. Metab. 2015, 59, 335-342. [CrossRef] [PubMed]

27. Liu, W.M.; Lai, S.J.; Lu, L.Z.; Shi, F.X.; Zhang, J.; Liu, Y.; Yu, B.; Tao, Z.R.; Shen, J.D.; Li, G.Q.; et al. Effect of dietary fatty acids on serum parameters, fatty acid compositions, and liver histology in Shaoxing laying ducks. J. Zhejiang Univ. Sci. 2011, 12, 736-743. [CrossRef] [PubMed]

28. Egert, S.; Kannenberg, F.; Somoza, V.; Erbersdobler, H.F.; Wahrburg, U. Dietary alpha-linolenic acid, EPA, and DHA have differential effects on LDL fatty acid composition but similar effects on serum lipid profiles in normolipidemic humans. J. Nutr. 2009, 139, 861-868. [CrossRef] [PubMed]

29. Morin, C.; Rousseau, E.; Blier, P.U.; Fortin, S. Effect of docosahexaenoic acid monoacylglyceride on systemic hypertension and cardiovascular dysfunction. American journal of physiology. Heart Circ. Physiol. 2015, 309, H93-H102. [CrossRef] [PubMed]

30. Sawada, T.; Tsubata, H.; Hashimoto, N.; Takabe, M.; Miyata, T.; Aoki, K.; Yamashita, S.; Oishi, S.; Osue, T.; Yokoi, K.; et al. Effects of 6-month eicosapentaenoic acid treatment on postprandial hyperglycemia, hyperlipidemia, insulin secretion ability, and concomitant endothelial dysfunction among newly-diagnosed impaired glucose metabolism patients with coronary artery disease. An open label, single blinded, prospective randomized controlled trial. Cardiovasc. Diabetol. 2016, 15, 121. [CrossRef]

31. Du, X.; Liu, Y.; Lu, L.; Wang, W.; Zeng, T.; Tian, Y.; Xu, X.; Shen, J.; Niu, D.; Lu, Y. Effects of dietary fats on egg quality and lipid parameters in serum and yolks of Shan Partridge Duck. Poult. Sci. 2017, 96, 1184-1190. [CrossRef]

32. Bassett, C.M.; Rodriguez-Leyva, D.; Pierce, G.N. Experimental and clinical research findings on the cardiovascular benefits of consuming flaxseed. Appl. Physiol. Nutr. Metab. 2009, 34, 965-974. [CrossRef]

33. Dodin, S.; Lemay, A.; Jacques, H.; Légaré, F.; Forest, J.C.; Mâsse, B. The effects of flaxseed dietary supplement on lipid profile, bone mineral density, and symptoms in menopausal women: A randomized, double-blind, wheat germ placebo-controlled clinical trial. J. Clin. Endocrinol. Metab. 2005, 90, 1390-1397. [CrossRef]

34. Lucas, E.A.; Wild, R.D.; Hammond, L.J.; Khalil, D.A.; Juma, S.; Daggy, B.P.; Stoecker, B.J.; Arjmandi, B.H. Flaxseed improves lipid profile without altering biomarkers of bone metabolism in postmenopausal women. J. Clin. Endocrinol. Metab. 2002, 87, 1527-1532. [CrossRef] [PubMed]

35. Cunnane, S.C.; Hamadeh, M.J.; Liede, A.C.; Thompson, L.U.; Wolever, T.M.; Jenkins, D.J. Nutritional attributes of traditional flaxseed in healthy young adults. Am. J. Clin. Nutr. 1995, 61, 62-68. [CrossRef] [PubMed]

36. Khan, M.J.; Gerasimidis, K.; Edwards, C.A.; Shaikh, M.G. Role of Gut Microbiota in the Aetiology of Obesity: Proposed Mechanisms and Review of the Literature. J. Obes. 2016, 7353642. [CrossRef] [PubMed]

37. Angelakis, E.; Armougom, F.; Million, M.; Raoult, D. The relationship between gut microbiota and weight gain in humans. Future Microbiol. 2012, 7, 91-109. [CrossRef]

38. Crovesy, L.; Ostrowski, M.; Ferreira, D.; Rosado, E.L.; Soares-Mota, M. Effect of Lactobacillus on body weight and body fat in overweight subjects: A systematic review of randomized controlled clinical trials. Int. J. Obes. 2017, 41, 1607-1614. [CrossRef]

39. Auffret, M.D.; Dewhurst, R.J.; Duthie, C.A.; Rooke, J.A.; John Wallace, R.; Freeman, T.C.; Stewart, R.; Watson, M.; Roehe, R. The rumen microbiome as a reservoir of antimicrobial resistance and pathogenicity genes is directly affected by diet in beef cattle. Microbiome 2017, 5, 159. [CrossRef] [PubMed]

40. Mao, G.H.; Ren, Y.; Feng, W.W.; Li, Q.; Wu, H.Y.; Jin, D.; Zhao, T.; Xu, C.Q.; Yang, L.Q.; Wu, X.Y. Antitumor and immunomodulatory activity of a water-soluble polysaccharide from Grifola frondosa. Carbohydr. Polym. 2015, 134, 406-412. [CrossRef]

41. Ley, R.E.; Hamady, M.; Lozupone, C.; Turnbaugh, P.J.; Ramey, R.R.; Bircher, J.S.; Schlegel, M.L.; Tucker, T.A.; Schrenzel, M.D.; Knight, R.; et al. Evolution of mammals and their gut microbes. Science 2008, 320, 1647-1651. [CrossRef]

42. Bredholdt, H.; Galatenko, O.A.; Engelhardt, K.; Fjaervik, E.; Terekhova, L.P.; Zotchev, S.B. Rare actinomycete bacteria from the shallow water sediments of the Trondheim fjord, Norway: Isolation, diversity and biological activity. Environ. Microbiol. 2007, 9, 2756-2764. [CrossRef] [PubMed]

43. Claus, S.P.; Ellero, S.L.; Berger, B.; Krause, L.; Bruttin, A.; Molina, J.; Paris, A.; Want, E.J.; de Waziers, I.; Cloarec, O.; et al. Colonization-induced host-gut microbial metabolic interaction. mBio 2011, 2, e00271-10. [CrossRef] [PubMed]

44. Li, L.; Batt, S.M.; Wannemuehler, M.; Dispirito, A.; Beitz, D.C. Effect of feeding of a cholesterol-reducing bacterium, Eubacterium coprostanoligenes, to germ-free mice. Lab. Anim. Sci. 1998, 48, 253-255.

45. Li, L.; Buhman, K.K.; Hartman, P.A.; Beitz, D.C. Hypocholesterolemic effect of Eubacterium coprostanoligenes ATCC 51222 in rabbits. Lett. Appl. Microbiol. 1995, 20, 137-140. [CrossRef]

46. Whon, T.W.; Kim, H.S.; Shin, N.R.; Jung, E.S.; Tak, E.J.; Sung, H.; Jung, M.J.; Jeong, Y.S.; Hyun, D.W.; Kim, P.S.; et al. Male castration increases adiposity via small intestinal microbial alterations. EMBO Rep. 2020, e50663. [CrossRef]

47. Kim, M.; Kim, J.; Kuehn, L.A.; Bono, J.L.; Berry, E.D.; Kalchayanand, N.; Freetly, H.C.; Benson, A.K.; Wells, J.E. Investigation of bacterial diversity in the feces of cattle fed different diets. J. Anim. Sci. 2014, 92, 683-694. [CrossRef]

48. Jiang, Y.; Ogunade, I.M.; Qi, S.; Hackmann, T.J.; Staples, C.; Adesogan, A.T. Effects of the dose and viability of Saccharomyces cerevisiae. 2. Diversity of ruminal microbes as analyzed by Illumina MiSeq sequencing and quantitative PCR. J. Dairy Sci. 2016, 100, 325. [CrossRef] 